\title{
El Camino Real en el Norte cordobés Defensa de la identidad y el patrimonio de la región
}

\author{
Noemi Goytia \\ Arquitecta \\ Profesora de la Universidad Nacional de Córdoba
}

\section{Introducción}

Analizar un paisaje cultural con rasgos históricos particulares, el Norte cordobés, donde el otrora importante Camino Real engarza sitios, paisajes, poblados, festividades, festivales y otras manifestaciones artísticas, significa un desafío, porque la región se encuentra hoy en franca decadencia. El reto consiste en consecuencia en impulsar su rehabilitación y puesta en valor a través de un trabajo de investigación sobre la gestión de sus recursos culturales para que ese Camino Real se convierta en el protagonista principal de una narración atractiva y en el elemento unificador y de enlace sobre el que se insertarán diferentes propuestas, tendentes todas a convertirlo en un estímulo para el desarrollo del territorio en su conjunto.

Para ello se hace necesario promover sus atractivos, y ofrecer condiciones y servicios que contribuyan al desarrollo de todos los lugares vinculados a través de él, con el apoyo de urbanistas, historiadores, sociólogos, antropólogos y economistas, y fundamentalmente, con los habitantes del lugar.

Por eso se está trabajando primordialmente en la conservación de los rasgos esenciales paisajísticos, ambientales, urbanísticos, arquitectónicos y de bienes artísticos y costumbristas tangibles e intangibles en la convicción de que no sólo se deben perseguir objetivos socio-culturales, sino asimismo económicos. Los proyectos incluyen el diseño de recorridos los nuevos corredores turísticos que complementen a las distintas variantes del Camino Real; la puesta en valor y la difusión de paisajes culturales de la región; la gestión de micro-emprendimientos que promuevan la ocupación de mano de obra local y especialmente, la educación formal e informal. En todos los proyectos y en su puesta en marcha se ha considerado de vital importancia esbozar mecanismos de participación ciudadana teniendo en cuenta la especial conciencia de los pobladores de esa región sobre el patrimonio del que son herederos y su sentido de pertenencia e iden-

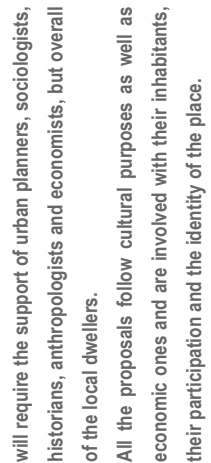

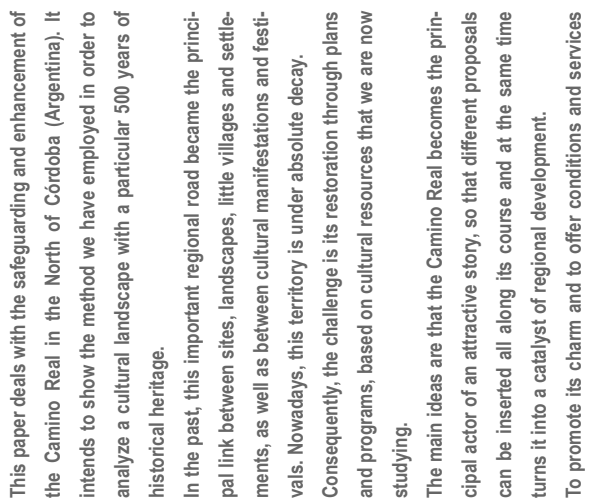

1. Proyecto en ejecución dirigido por la arquitecta Noemi Goytia, Codirigido por la Magister Lidia Samar y con la participacion de . los siguientes investigadores: Myriam Almandoz, Joaquín Peralta, Clementina Zablosky, Guillermo Ferrando, Alejandro Romanutti, Florencia Caeiro, Diana Cohen, Paula Pina Marquez y la colaboración de Silvia Oliva, Mabel Burón, Griselda Villela, Pablo Ortiz Díaz, Lorena Fernández, Juan Pablo Scarabello. Asesores Sara Rossi y David Malik de Tchara 
tidad con su lugar. ${ }^{2}$

\section{Marco conceptual}

Se tiene ante sí lugares que desafían al tiempo; hitos o nodos que acumulan la memoria combatiendo el olvido, evocaciones permanentes de personas o instituciones fundacionales, luchando contra el paso del tiempo. Mitos y ritos, memoria y permanencia, son términos que se vinculan al paisaje cultural, al patrimonio y a la identidad cultural en el Norte Cordobés. Preservarlos, es el desafío.

Se ha definido al patrimonio histórico cultural como una propiedad colectiva heredada de los ancestros; como un bien cultural o material cargado de significados para un grupo social, que ha trascendido las circunstancias temporales adquiriendo a lo largo de la historia nuevas cargas semánticas enriquecedoras, y que se preserva para la propia satisfacción personal, individual o social, pero esencialmente para transmitirlo a las generaciones futuras.

Dentro de este enfoque se ha considerado la región y su paisaje natural, apropiado y /o modificado, así como sus centros urbanos, patrimonio de sus habitantes, sin importar la modestia del patrimonio, puesto que es el reflejo de la cultura y de los modos de ser y habitar de sus hombres.

Este patrimonio constituye su identidad, término que aparece como tabla de salvación de una generación que ha perdido la fe en los grandes proyectos y en el progreso, y que vuelve la espalda a los valores generales, proponiendo una actitud de compromiso particular con lo que ya existe: con la historiay las tradiciones, para a partir de ellas, mirar al futuro.

La identidad aparece entonces como la resultante de un complejo y dinámico proceso de interacciones entre el habitante y el conjunto de circunstancias en las que se halla inmerso, rescatando de esta manera la reflexión Ortegiana: "yo, soy yo y mis circunstancias". Espacio-tiempo son sus variables, las que podría-

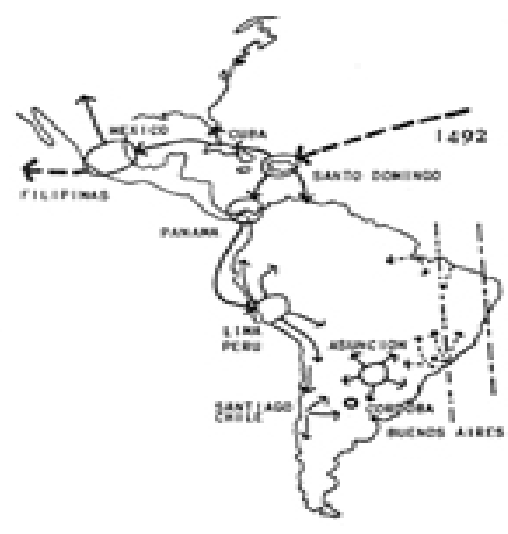

El enfoque que se propone y las técnicas de análisis a emplear están muy relacionados con los ya experimentados en otros trabajos que cubren áreas parciales de la provincia, Se trata de los estudios ya publicados sobre Poblados Históricos del Norte Cordobés (Foglia, M. E. y Goytía, N. Córdoba, 1993).

Existe un estudio aún no publicado más detallado tanto desde el punto de vista urbanístico como histórico: Rehabilitación de los poblados del Norte Cordobés: el caso de la Villa de Tulumba (Foglia, M. E., Guidi, F., Gotilla, N., Rossi, S., Schultess, W., Baigorría, l.), investigación realizada por encargo de la Comisión Nacional de Museos, Monumentos y Lugares Históricos en 1987-88 (ver artículo en Medio Ambiente y Urbanización № 27, Buenos Aires, 1989) y otro sobre "Artesanías del Norte Cordobés" realizado por Lidia Samar, Paula Pina Marquez y Gustavo Erni, resultado de las investigaciones avaladas por Subsidio de la Agencia Córdoba Ciencia y por Becas de la Secretaría de Extensión de la Universidad Nacional de Córdoba. 
mos llegar a particularizar y a caracterizar como: situación geográfica, topografía, clima, etnia, costumbres, lengua, creencias, etc. Ellas operan consciente o inconscientemente sobre los modos de comportamiento y de expresión del hombre, le confieren un "carácter" a su accionar y definen sus peculiaridades en función de un sistema de valores ajustado a su horizonte cultural.

Ahora bien, se ha dicho que el hábitat no es permanente, el hombre lo va modificando, lo destruye, lo reconstruye de acuerdo a sus cambiantes necesidades, tanto físicas como psíquicas y culturales, y este proceso de cambio es en definitiva la historia del lugar. En consecuencia, la identidad no es algo congelado en el tiempo. Entendemos el cambio como el agente necesario en los procesos de renovación de la identidad, el que actúa con espíritu renovador sobre los elementos obsoletos, que a modo de enmarañada trama encubren los procesos necesarios de transformación a que están sometidos los pueblos; pero también entendemos que el cambio selecciona y confirma las permanencias y que a modo de extraordinaria alquimia condensa, sintetiza y elabora el espiritu de los nuevos tiempos.

Descubrir las relaciones entre el habitante y su lugar es el desafí inicial de una propuesta para la región, teniendo en cuenta que ellas son misteriosas y complejas al punto de aparecer a veces como mágicas o míticas. El hombre de la montaña, el del desierto, el del bosque, el de la llanura, parecen tener diferentes maneras de ver y sentir, de vivir y valorar, de medir sus tiempos y relacionarse con sus lugares; de expresar, a través de sus cantos y silencios, sus goces y sus retos, sus angustias y esperanzas.

Esta última afirmación obliga a trabajar con varias escalas y si empezamos por las macro visiones, el primer paso atañe a definir nuestro peculiar continente.

La identidad latinoamericana enfrenta un desafío, ya que se está trabajando con un concepto de alto compromiso emocional, no normado, entre el grupo social y los objetos que constituyen su entorno. Se trata de un crisol de modelos cuya amalgama no acaba de consolidarse puesto que es un proceso histórico cambiante. En general tenemos que convenir que los modos de integración de culturas en nuestro continente revisten y revistieron las más diversas facetas a través de la historia, y que éstos van desde la más abierta imposición de modelos, pautas y valores en una cultura sojuzgada, pasando por la importación gustosa de ideas y formas de vida atractivas (cultura francesa y costumbres inglesas, en el siglo XIX), a las actuales más sutiles formas de apropiación por los medios masivos de comunicación o de la literatura especializada según sea el nivel a que está dirigido el mensaje.

América Latina ha sido, y es aún, sede receptora de estos procesos de asimilación cultural en forma
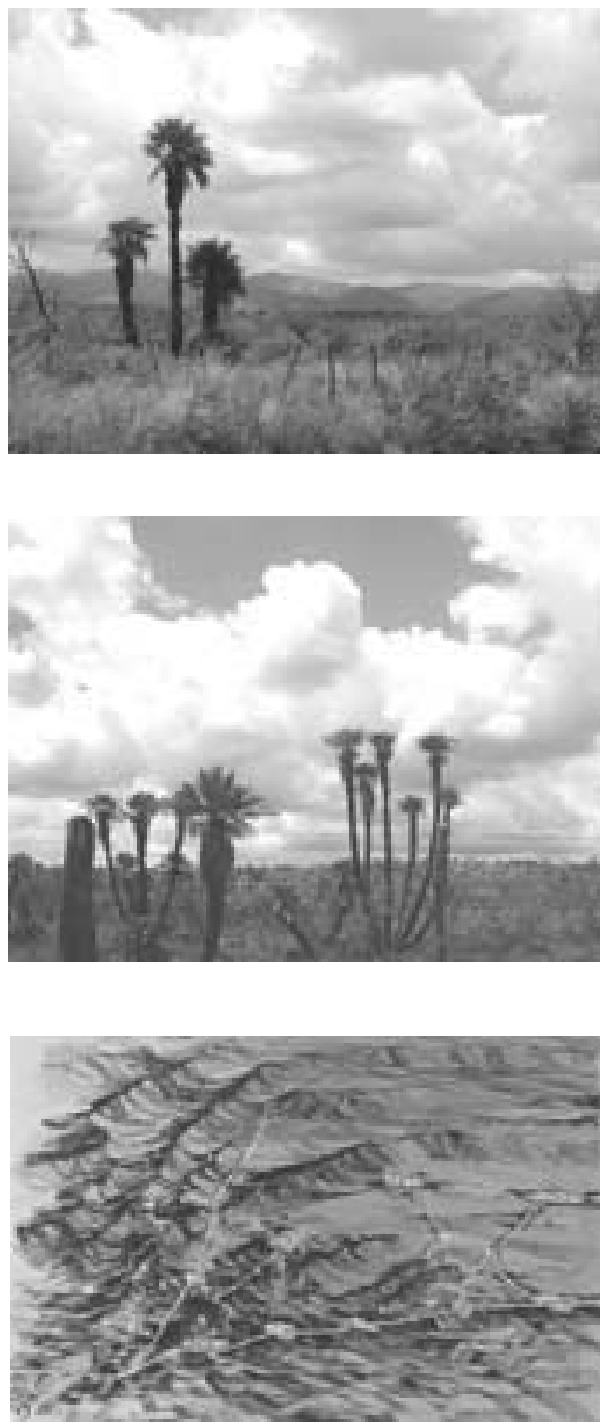
muy dinámica y diversa. Desde la colonia a nuestros días se han ido sucediendo ininterrumpidamente los procesos de adaptación e integración o de mera recepción, con que nos encontramos en cada una de las regiones y en cada momento histórico de su evolución. A la imposición de valores, modelos, y símbolos que sucedió a la conquista, siguió un extenso período de adaptaciónque generó el riquísimo marco de una identidad sincrética. Lo mestizo, como expresión de un nuevo modo cultural, dejó su impronta netamente reconocible desde Méjico hasta el Sur, con las particularidades del caso, según características regionales, étnicas y aún raciales, por la corriente de sangre negra incorporada compulsivamente en el trabajo esclavo. Es sólo a mediados del siglo XIX que se produce una nueva situación posterior a las revoluciones americanas marcadas por las ideas de la revolución francesa y por el impacto de la revolución industrial que desde los países centrales promueve el marco ideológico y económico de la nueva situación. A esto tendremos que agregar en algunas regiones la fuerte componente migratoria, que como producto de las crisis europeas, arriba en forma creciente y desordenada a estos jóvenes países en gestación, traspasando pautas, costumbres, valores y tradiciones que llegan a principios del siglo XX a conformar un verdadero mosaico de razas, etnias, culturas e ideologías y que van acomodándose a la nueva situación, hibridándose y conformando el rico caldo de cultivo de una nueva expresión sincrética y multiforme todavía en gestación. Si a esta operación aún no totalmente consumada por razones de tiempo y de decantación histórica, por vías reales, le agregamos la que se produce por vías formales a través del circuito de comunicación originado en los países centrales y cuyas transferencias directas crean verdaderas interferencias en el proceso de asunción de la identidad por parte del cuerpo social en su conjunto, podemos vislumbrar la complejidad del problema, donde es bien endeble el límite entre estas identidades muy frescas y los riesgos de hibridaciones demasiado difusas y de enajenaciones culturales totales, lo que conlleva a la pérdida de la identidad.

Enfocando con un zoom nuestra temática en este contexto al objeto de limitar nuestra visión a una región definida, acudir al concepto de paisajes culturales puede ser de gran ayuda para preservar huellas tan dispares de su historia, de su patrimonio y en definitiva de esta identidad sincrética. Significa la posibilidad de encontrar los mecanismos de protección necesarios para su preservación a la vez que la rehabilitación de regiones en muchos casos como la que aquí se presenta, palimpsesto de manifestaciones diferentes, degradadas económica y socialmente. Significa engarzar los valores, tal vez modestos, de poblados y paisajes naturales que en su conjunto se potencian y cobran un interés diferente. Significa asociar a elementos de diferente valor, muchas veces irrelevantes si se les considera de forma aislada, pero intere-
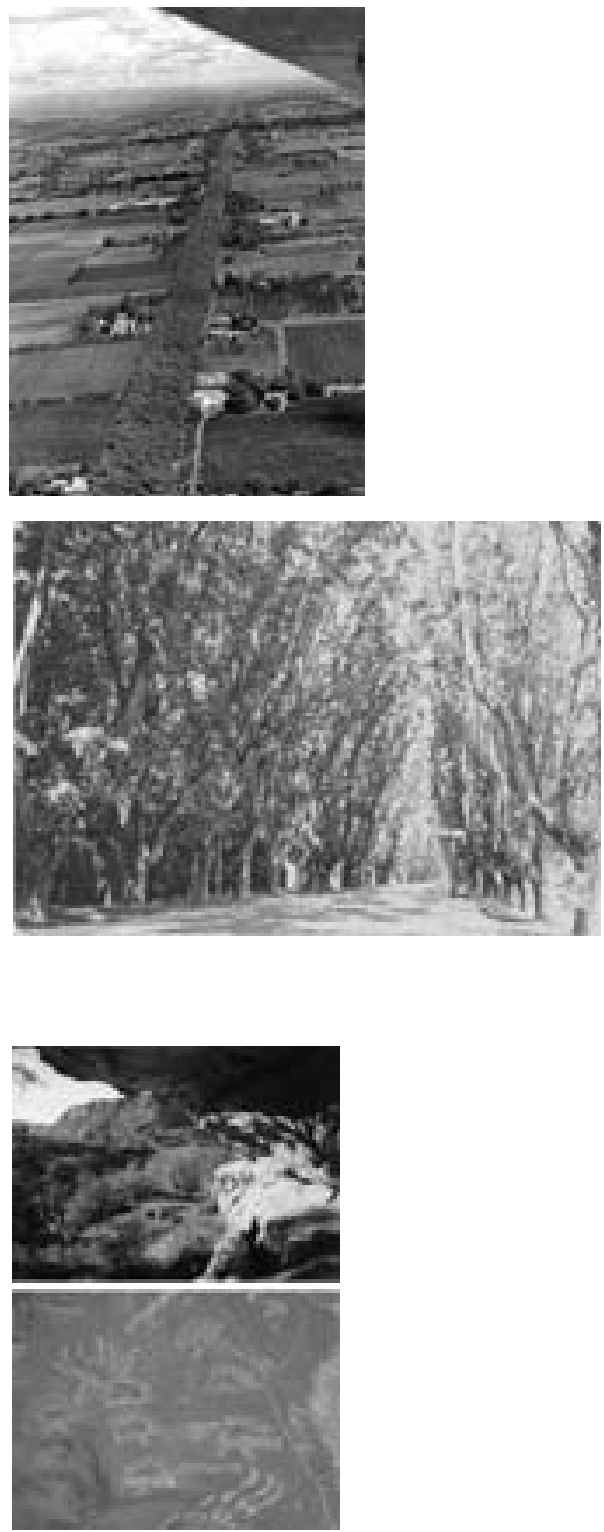
santes como conjunto patrimonial, ya sea natural o cultural, junto con los grandes monumentos, en una visión no puntual de hechos aislados, sino como un paisaje integral amplio con lo que el monumento se contextualiza y cobra mayor vitalidad. Significa comprender la vida que emana de los testimonios del pasado, apreciar sus medios de producción en la historia, sus expresiones artísticas y artesanales en una visión holística del lugar. Significa difundir, con carácter educativo y recreativo, lugares paisajísticos valiosos y de memoria histórica para la población en general, muchas veces ignorados u olvidados por los circuitos habituales del turismo. Significa, asimismo, repartir compromisos e inversiones entre el estado y las fuerzas particulares, en la asunción de la tarea de creación y mantenimiento del área y muy especialmente rescatar la autoestima de la población consolidando una comunidad en su lugar de origen que, de otro modo, siempre está dispuesta a emigrar en busca de mejores oportunidades.

En otras palabras, significa la posibilidad de compatibilizar valores económicos aprovechables con el concepto de patrimonio cultural a través de una diversidad de programas que desde las áreas técnicas estatales, particulares o universitarias, se diseñen, demostrando cómo el patrimonio cultural posee un valor económico y es capaz de ser incorporado al circuito productivo.

En síntesis el patrimonio cultural pasa a establecer el eje posible de un desarrollo integrado del conjunto de centros de la región y de sus diferentes manifestaciones culturales, reemplazando el enfoque local parcializado de búsqueda de recursos individuales, en la mayoría de los casos inexistente en el contexto de una economía estancada

Se trata entonces de experimentar un nuevo enfoque frente al problema, partiendo del concepto de Paisaje Cultural aplicado a una región específica

\section{Presentación del lugar elegido para la experiencia: el Norte Cordobés}

\section{El paisaje}

La provincia de Córdoba es una de las unidades político-administrativas más importantes de la Argentina, por su población, su economía, su dimensión y su estratégica situación en el centro mismo del país.

En su territorio se produce el encuentro de las planicies del Este con las Sierras pampeanas o centrales, cordones montañosos que alternando con valles estructuran en términos geomorfológicos la mitad occidental de la Provincia.
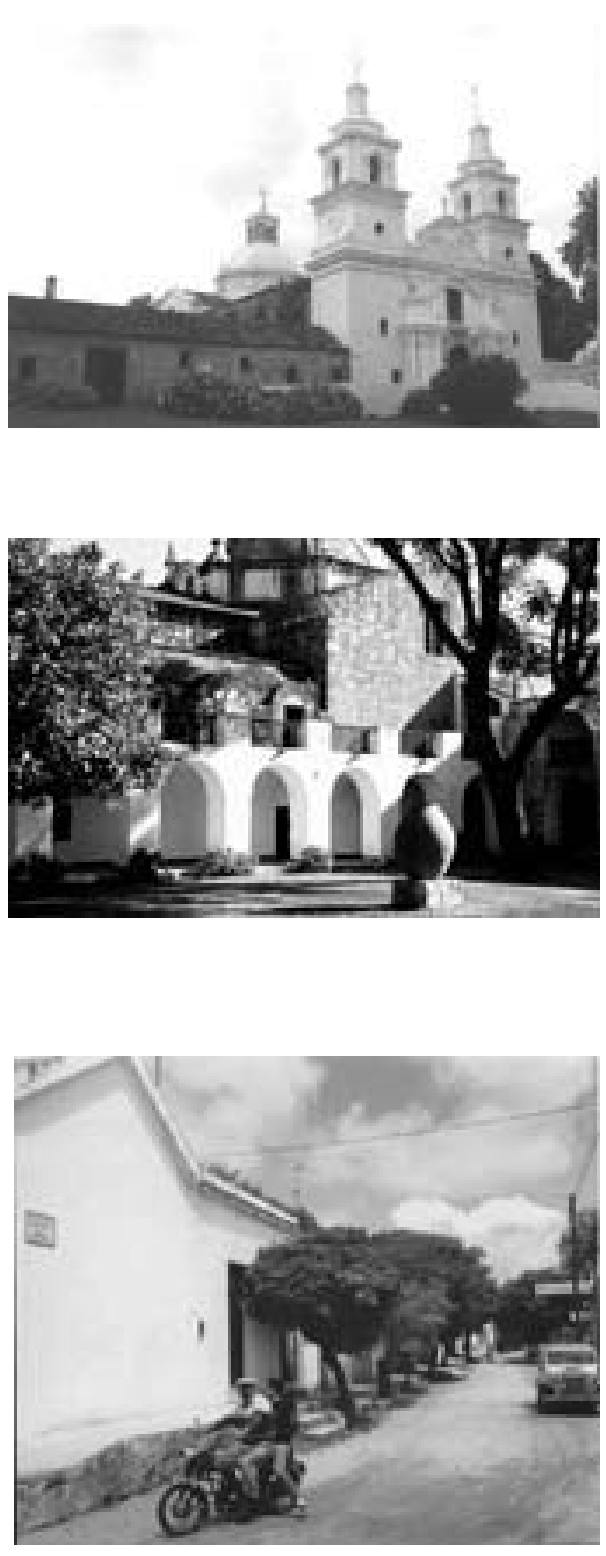
La región que nos interesa ocupa la parte del centro Norte de Córdoba y la hemos caracterizado sintéticamente según sus aspectos físicos, geográficos, demográficos y económicos.

De todo el Norte de la provincia, la zona centro montañosa, el valle del Deán Funes y la vertiente y faldeos orientales de las Sierras del Norte, configuran la zona más apta para la actividad y asentamiento humano, con sus valles temporalmente regados por cursos de agua, aptos para el desarrollo de producción agraria y la considerable extensión de los faldeos orientales donde se dan la cría y engorde de ganado, y a partir de su deforestación, de la creciente agricultura. El bosque natural serrano que cubre las laderas se caracteriza por una vegetación arbustiva espinosa predominante y pastos duros, donde se destacan quebrachos, algarrobos, molles y espinillos, alternados por extensa zonas de palmeras caranday, rasgo especial de la región. Hacia el Este la vegetación cambia hacia el monte de llanura donde predominan las matas y los pastos

Esta zona es extensa. Conforma un triángulo que como cuña sienta su vértice Sur en la ciudad de Córdoba, distante hasta su base en el Norte $175 \mathrm{~km}$, De oriente a poniente, en su parte más dilatada, abarca aproximadamente $70 \mathrm{~km}$, extendiéndose entre las Salinas Grandes al Oeste y la depresión de la laguna de Mar Chiquita en el Este.

Es la zona que ocupaban las etnias Comechingones al Oeste y Ssanavironas al Este; tribus pacíficas y sedentarias de aborígenes, de cultura relativamente desarrollada a la llegada de los españoles. Es la que aprovecharon los conquistadores europeos para fundar sus primeros asentamientos.

Un rico paisaje al pie oriental de las sierras chicas, constituye el soporte natural de esta región. Los pequeños poblados se sitúan y dialogan con vallecitos angostos e irregulares, y laderas suaves de las estribaciones de las bajas ondulaciones del terreno, atravesado por arroyos de aguas claras, son recorridos por angostos caminos secundarios. Cielo azul intenso y aire seco, visuales hacia el infinito en la llanura hacia el Este, donde se dibuja el perfil de especies arbóreas exógenas incorporadas por el hombre de campo señalando su casa. En este paisaje hoy pueden verse grandes extensiones de plantación de soja divididas por alambrados en parcelas cuadrangulares, que lamentablemente avanzan provocando la deforestación natural del lugar.

Dentro de la región hacia su extremo Norte nos encontramos con el Parque arqueológico del Cerro Colorado, principal reserva de pictografías precolombinas de la provincia y que junto a Ongamira, son los testimonios más destacados de la cultura aborigen local. Cerro Colorado es un lugar muy interesante del
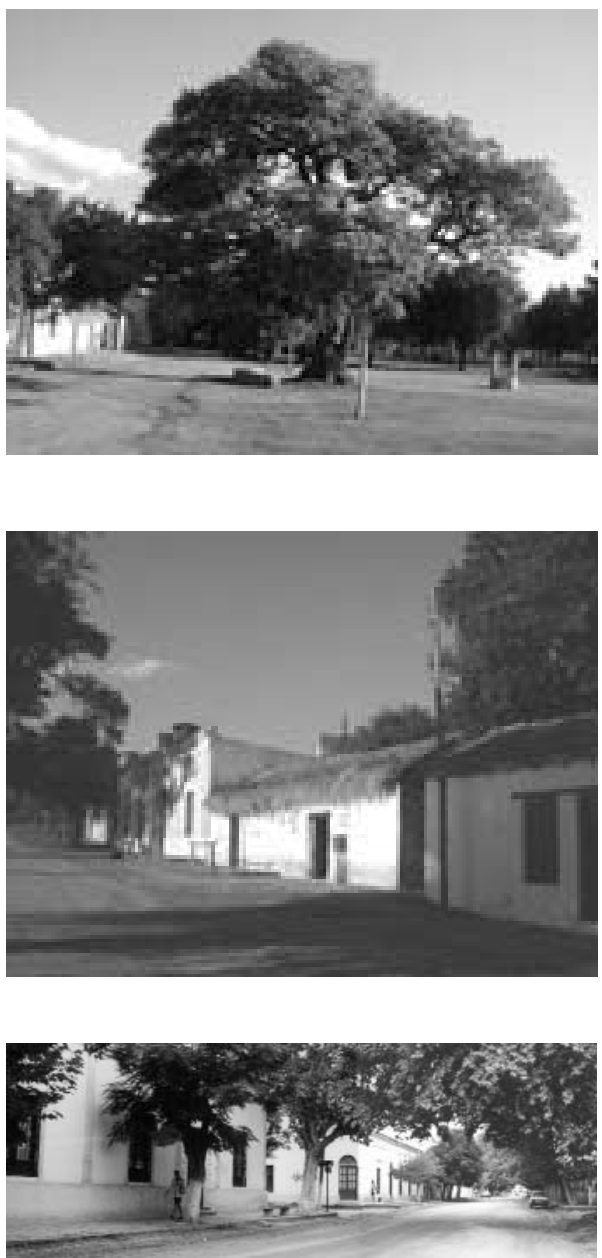
Norte cordobés. Ubicado en un paraje de singular belleza natural que bordea la quebrada del Río Los Tártagos de abundante vegetación autóctona: zona de monte espeso, de visuales quebradas, atravesado por numerosos arroyos, combina el interés por las extraordinarias pictografías zoomórficas, abstractas y de figuras humanas plasmadas en cuevas y cornisas rojas, con el encanto del paisaje natural.

\section{Los Asentamientos y su historia}

Hemos dicho que como hilo conductor de nuestro relato tomamos el Camino Real, conocido así porque a través de él se inició la consolidación de la población y la implantación de una cultura peculiar de este territorio, que nos ha quedado como legado histórico. Este camino irá engarzando poblados paisajes y comunidades, testimonios de lo aborigen, de la conquista española, huellas importantes del siglo XIX, y de su estado actual. Es en suma un libro elocuente de historia a recorrer, que enseña sin hablar, que transmite saber a través de los testigos materiales e inmateriales del pasado.

Por la zona del Norte cordobés penetró al actual territorio provincial la colonización hispánica, generando en el proceso una serie de asentamientos, cuyas primeras funciones fueron postas, capillas y estancias.

Ellas estructuraron con el tiempo una organización territorial constituida por centros relativamente vecinos en el espacio localizados sobre tres ejes fundamentales, que como trípode convergen en un vértice en la ciudad de Córdoba.

¿Qué buscaban los españoles con estos asentamientos? Etapas de un camino obligado por tierra hacia el Océano Atlántico. Un nexo que vinculase las áreas mineras del Alto Perú, en especial Potosí, con un puerto que llevase más directamente a España, sin tener que pasar por el proceloso Cabo de Hornos o el estrecho de Magallanes.

La fundación de Córdoba logra este punto estratégico de enlace de rutas que conduciría de forma más directa hacia el Río de la Plata. Su fundación inicia la real ocupación del territorio, en general de la mano de mercedes otorgadas a los primeros colonizadores (Villa del Totoral, Villa de Quilino, Ischilín, Caminiaga, etc) o bien a la acción evangelizadora de la Iglesia en su afán de convertir a los indígenas de la región (Santa Catalina, San Isidro). El fundador de Córdoba en su conquista del territorio utiliza el camino construido y transitado por los indios Sanavirones y Comechingones, pero a partir del siglo XVII y XVIII se abren nuevas vías alternativas que amplían la posibilidad de generar nuevos asentamientos

Dentro de la región le prestaremos especial atención a los poblados históricos. Se trata de centros urba-
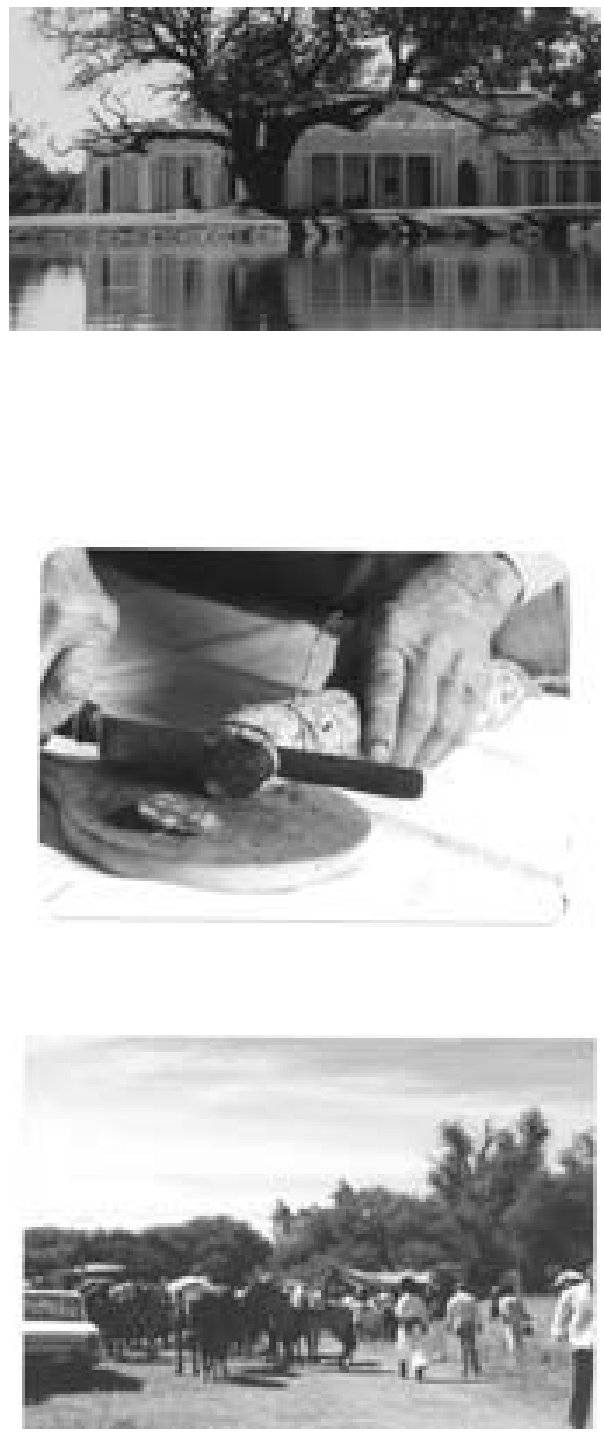
nos pequeños y fundados en los primeros tiempos de la conquista española, hace 500 años, que han sufrido a partir del siglo XIX, estancamiento o detención de su proceso económico y social. Como consecuencia no presentan renovación urbana y edilicia, cristalizando un paisaje ambiental reflejo de épocas pasadas. El patrimonio heredado, tanto arquitectónico como intangible, se ha mantenido como testigo de tales épocas históricas. Con pocas excepciones poseen monumentos arquitectónicos relevantes. Su paisaje tiene como base un tejido de conjunto casi intacto, significativo como testimonio de su pasado, pero desconocido fuera de su medio y en franco proceso de deterioro. Sin embargo dentro de la región se encuentran dos de los conjuntos arquitectónicos más extraordinarios del país: las estancias jesuíticas de Santa Catalina y San Isidro en Jesús María, declaradas por UNESCO patrimonio de la Humanidad.

El paisaje urbano que da identidad a la región tiene marcadas las huellas de la herencia española. Esos rasgos homogeneizarán con gran presencia el paisaje urbano resultante

El siglo XIX es un período de grandes cambios para la región. La independencia, el largo período de anarquía y finalmente el proceso de organización nacional, ya pasado el medio siglo, significaron para estos lugares el protagonismo de destacados personajes de la región que han dejado huellas en la memoria colectiva de sus habitantes

Es a partir de la reconversión de la economía del país entre los años1870 y 1890 que la estrella del lugar declina. El paso a una economía capitalista agro exportadora centrada en la explotación de la pampa húmeda cambia la organización territorial de la Argentina y se genera el conocido esquema en abanico convergente en la capital, el Puerto de Buenos Aires. Simultáneamente se produce la pérdida de importancia del ganado mular al haber sido sustituido por otros medios de transporte, cuando la cría y engorde de estos animales constituían una parte significativa de la base económica de la región. Solo quedó, entonces, una ganadería vacuna y caprina extensiva, sobre las bases de unas las características geográficas apropiadas, el escaso recurso de pasturas del medio y la introducción de los alambrados que agravan el problema de la cría extensiva.

Todos estos factores deterioraron el desarrollo del Norte Cordobés otrora relevante. Esto se traduce en una disminución de población que emigra en busca de nuevos trabajos y sólo quedan en estos centros gente mayor, ancianos, orgullosos de su linaje, de su patrimonio ambiental heredado, pero en franco deterioro, y en constante lucha para lograr ayuda estatal, único medio para su subsistencia. Es elocuente el caso del Departamento de Río Seco, que pasa de ocupar el $2^{\circ}$ lugar en el rango poblacional provincial en
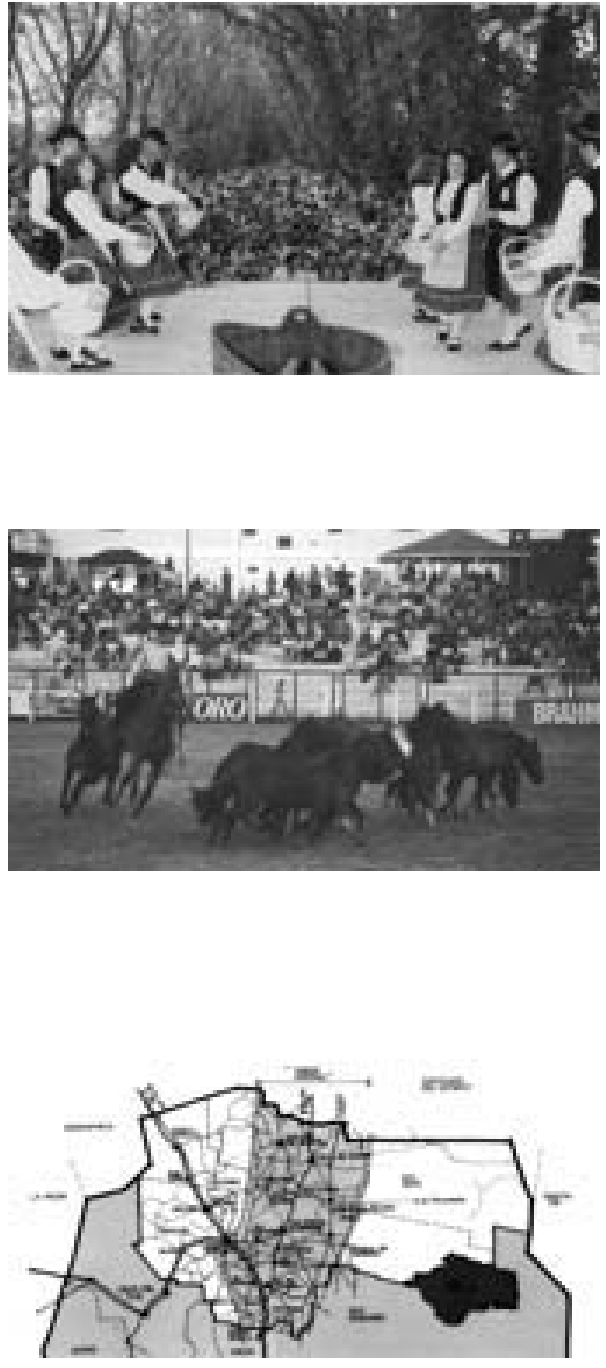
1840, al $9^{\circ}$ lugar en 1860. Si toda la región en 1869 poseía el 18\% de la población de la provincia, en 1895, sólo era del $13 \%$ y ya en 1914 sólo del $6,6 \% .{ }^{3}$

El cambio económico complementado por la introducción del ferrocarril, el telégrafo, la inmigración, especialmente europea, y cultivos en gran escala, incidirá en el cambio y reordenamiento de las regiones del país. El norte cordobés sufrirá así una marginación de gran parte de sus poblados, que quedan excluidos de los recorridos de las vías férreas y más adelante ya en el siglo XX, de las carreteras troncales, comunicándose únicamente por carreteras secundarias. Es el caso de San Francisco del Chañar, de Villa María del Río Seco, de San Pedro Norte, de la Villa de Tulumba, de San José de la Dormida, de Ischilín, de Caminiaga, de Santa Catalina, de Villa del Totoral y de Villa de Quilino. En cambio florecen poblaciones alrededor de las estaciones del ferrocarril, antiguamente menos importantes como Las Peñas, Macha, Avellaneda, Jesús María, Quilino y Deán Funes. Estos tres últimos se constituyen en centros polarizadores de funciones regionales, rol que mantienen hasta hoy en día Deán Funes y Jesús María. Por el contrario Las Peñas, Macha, Avellaneda y Quilino, al desaparecer el ferrocarril en la segunda mitad del siglo XX, entran nuevamente en franca decadencia.

Los poblados marginados crecerán muy lentamente, manteniendo su trazado y su arquitectura tradicional. Los nuevos introducirán tipologías arquitectónicas y tecnología traída por las firmas inglesas explotadoras de las redes ferroviarias: estaciones, almacenes, silos, señalizaciones. Aparece entonces el ladrillo visto con junta tomada al ras, techos de tejas planas, o de chapas de cinc, columnas de hierro de fundición, cenefas de chapa o madera en los aleros y pisos cerámicos.

En estos pueblos aunque se conserva la manzana cuadrangular, se introducen modificaciones, al organizarse alrededor de la estación ferroviaria abandonando el trazado isótropo alrededor de la plaza, característico de los pueblos de la colonización española.

Los inmigrantes italianos que llegaron a partir de 1876 se asentaron en el vértice sur de la región,dando a ese lugar una impronta diferente. Más al norte sólo llegaron inmigrantes sirios y libaneses, que se dedicaron fundamentalmente al comercio, sin introducir cambios en el paisaje físico de las poblaciones, aunque sí en las costumbres y modos de vida. Fueron, en este sentido, mucho más absorbidos por el medio que los friulanos de la Colonia Caroya.

3. Terzaga, A. Geografía de Córdoba. Editorial Assandri. Córdoba, 1963 
Colonia Caroya es un caso especial. La colonia, promovida y gestada por el gobierno nacional, como parte de su política de poblar el territorio, fue una de las primeras fundadas en el país y sentó las bases de muchas otras que luego le siguieron en todo el territorio argentino, en especial, en la pampa húmeda y en los valles de la Patagonia. Estos esforzados colonos han dejado su huella en el poblado. Si bien el reparto de tierras se hizo según una cuadrícula de grandes dimensiones para permitir el uso de solares como chacras y quintas, la configuración de anchas calles arboladas y en especial una avenida de plátanos espectacular, junto a la imposición de un lenguaje con rasgos neoclásicos a tipologías de vivienda semirrurales tradicionales y al uso del enfoscado exterior imitando piedra, jerarquizando el ingreso con molduras, guardapolvos, obras de mano de obra especializada, el frentista , crean un paisaje urbano muy singular que se mantiene aún hoy con todo su encanto. A su particular paisaje debe sumarse como atractivo todo un modo de vida y de producción artesanal de vinos y fiambres, unido a sus celebraciones con participación activa de todos sus habitantes. ${ }^{4}$

El frentista, oficio característico de los italianos llegados en gran número de Italia, tuvo un rol especial en la imagen urbana de muchos de estos pueblos. Se trasladaba de pueblo en pueblo, lo que contribuyó a homogeneizar la arquitectura de la región. Se generaliza entonces el uso de tirantería de hierro con bovedillas y cubierta de cinc como techo, las paredes pintadas con dibujos geométricos realizados con moldes, los mosaicos calcáreos como cubierta de piso con dibujos en color, etc.

La influencia de estos constructores italianos se hace notar en edificios mucho más significativos como las iglesias de la Villa de Tulumba, de San Francisco del Chañar y de San Pedro Norte, entre otras.

A este paisaje debe agregarse la aparición de grandes "estancias" en la zona, con casas pertenecientes a dueños de grandes extensiones de campo, muy amplias y destacadas que son testimonios de un bienestar y gusto por el buen vivir de las clases dirigentes que volvían a su terruño, en verano quizás por añoranza, quizás a gozar de un mejor clima que en sus propiedades de la llanura productiva. Se trata de grandes casonas, al modo de Villas italianas o de modestos palacios franceses, proyecto de constructores reconocidos. En general son de una sola planta con galerías de columnas neoclásicas en todo su perímetro y rodeadas por parques de gran extensión producto del diseño de algún paisajista reconocido, con estanque,

4. Fue ese el motivo para realizar allí la experiencia piloto sobre un paisaje cultural en agosto de 2004 con la participación de profesionales y alumnos de postgrado del país y del extranjero. Alli se analizaron y diseñaron proyectos y se propusieron políticas e instrumentos relativos a la gestión de recursos culturales para el desarrollo local, mediante programas socialmente relevantes y económicamente viables. 
añosos e interesantes árboles exóticos y arbustos que enmarcan con acierto a la arquitectura. Se trata de microclimas dignos de visitarse, verdadero recreo para su vivencia, y es posible hacerlo ya que algunas están convertidas hoy en hoteles como La Paz, La Verde y La Carolina.

Los pueblos actualmente se comunican a través de una red vial principal interregional, rutas 9 y 60 , en los lados exteriores del triángulo y caminos regionales que hacen centro en los pueblos principales proveedores de servicios como Jesús María, Deán Funes, Villa del Totoral, Villa de María de Río Seco, Villa de Tulumba, o San Francisco del Chañar, todos ellos cabeceras de su Departamento.

\section{Patrimonio intangible}

Dentro del concepto de patrimonio cultural hemos asignado un papel relevante a las expresiones intangibles como las artes, (música, poesía literatura) y también a aquellas tangibles, que en general son relegadas en su valoración, como son las artesanías y la producción gastronómica típica de cada lugar. Las conmemoraciones, las festividades, la artesanía, las leyendas, la música, la pintura, la poesía son los mejores reflejos, los más fieles, de modos de vida persistentes que, en conjunto, permiten descubrir la historia del lugar y contribuir así a guardar la memoria histórica del país.

Caracterización y valoración de los poblados y sus manifestaciones según su origen y grado de reconocimiento:

a) Poblados reconocidos a nivel nacional: En general son de origen colonial, poseen importantes ejemplos de arquitectura de ese período acompañados por tejido urbano del siglo XIX. Conservan un destacado patrimonio cultural y costumbrista de artesanía y fiestas tradicionales. Es el caso de Jesús María, Santa Catalina, Ischilín, Colonia Caroya, Sinsacate.

Están acreditados a nivel nacional sus festivales, en especial el Festival de la Doma y el Folklore de Jesús María, la Fiesta de la Sagra, y la de las comidas típicas de Colonia Caroya.

En Ischilín se desarrolla la Fiesta de la Virgen del Rosario a principios de octubre; y durante todo el año, es de especial interés el Museo Fader, con las pinturas de uno de los mejores artistas impresionistas del país. Ischilín es hoy centro de turismo exclusivo de alto nivel y ha agregado a su interés la incipiente actividad agrícola con los más cuidadosos saberes del oficio de cultivo de vid para la producción artesanal de vinos.

En Santa Catalina y San Isidro en Jesús María se dan importantes conciertos en el ámbito de las igle- 
sias y San Isidro tiene el Museo histórico más importante del Norte cordobés, con valiosas colecciones de objetos precolombinos y coloniales.

b) Poblados medianamente conocidos a nivel nacional sin monumentos coloniales pero que se caracterizan por su paisaje urbano homogéneo, en general del siglo XIX, con algún monumento de ese período:.Villa del Totoral, Villa de Tulumba.

Sus festividades aunque sin la difusión y reconocimiento de las incluidas en el grupo anterior son de alto interés y dignas de mención.

En Copacabana se realiza la fiesta de la virgen de la Candelaria el 2 de febrero. Posee la mejor artesanía de la palma.

Villa de Tulumba y Totoral, conservan una impronta tradicional en las costumbres, modos de vida y comidas. Generan diversas manifestaciones culturales, religiosas y recreativas en especial durante los meses de verano.

c) Poblados escasamente conocidos fuera de su región:

c.1) aquellos en que predomina el paisaje urbano de casonas y templos del siglo XIX. Algunos conservan expresiones de fiestas tradicionales y artesanía. Villa María del Río Seco, San Francisco del Chañar, San José de la Dormida.

c.2) Caseríos irregulares que no llegan a configurar la imagen urbana más que alrededor de una plaza y donde predomina el perfil de la iglesia: San Pedro Norte, San Pedro de Toyos.

c.3) Pequeños poblados o caseríos alrededor de la estación de ferrocarril: Quilino, Avellaneda Macha.

c.4) Monumentos arquitectónicos aislados en el paisaje natural que aparecen sorpresivamente en el recorrido: Estancias como La Paz, La Verde, Bajo de Correa, Santa Ana; capillas y templos como El Carmen, San Pedro Viejo; postas, como Sinsacate

Ya se ha destacado como lugar singular en la región el yacimiento arqueológico del Cerro Colorado, que junto a Ongamira son las únicas expresiones del patrimonio aborigen en la zona.

En el caso del patrimonio intangible, de los pueblos caracterizados en este último grupo consideramos que es escasamente conocido, pero es importante tenerlo en cuenta para fomentar su desarrollo y difundirlo dado que corre el riego de que si no se lo apoya desaparezcan expresiones especiales de su arte y artesanías al ser pobladores ancianos en general los que poseen el saber y dominio de las técnicas para 
estas manifestaciones

Tienen lugar en estos pueblos festivales o festividades religiosas de menor relevancia, aunque no carentes de autenticidad como el Festival de la Palma en San Francisco del Chañar o la procesión de la Candelaria en Caminiaga con su desfile de gauchos.

En Villa María del Río Seco está el Museo Leopoldo Lugones en la casa que perteneciera a este escritor. Allí se exhiben muebles y documentos de su propietario. Son una buena lección de un modo de vida a fines del siglo XIX y principios del siglo XX. Se desarrollan además actividades literarias en el mes de junio. Villa María de Río Seco posee un interesante Museo Arqueológico Municipal con documentación de las pictografías del Cerro Colorado.

Interesa estudiar esta región porque los cambios socio-económicos producidos a partir de la crisis del 2001 han transformado a la Argentina en un país receptor de turismo dando como resultado la reconversión económica en ciertas zonas, apoyadas en la explotación de sus recursos naturales y paisajístico-culturales con alcance internacional. Porque esta situación produjo una disminución notable en la emisión de turistas hacia el exterior, y una mayor demanda de alojamiento y servicios en las zonas tradicionalmente turísticas argentinas: la costa de la provincia de Buenos Aires, Misiones Jesuíticas y Cataratas, los glaciares patagónicos, la Quebrada de Humahuaca, el Valle de Punilla y últimamente, el Valle de Calamuchita.

Y esto nos estimuló a generar alternativas de preservación, promoción y gestión de los paisajes culturales como patrimonio y como atractivo para un turismo nacional y regional hacia una región hoy marginada pero con tantas potencialidades como el norte Cordobés, de modo de mejorar su capacidad de aprovechamiento de sus valores ambientales, tratando de contribuir a su desarrollo social y económico.

Porque sintéticamente podemos afirmar que el Camino Real en el Norte cordobés es capaz de poner en valor integralmente huellas importantes y diversas de la historia traducidas en importantes monumentos del pasado, que no se limitan sólo al patrimonio jesuítico y a la valiosa reserva arqueológica y ambiental de Cerro Colorado, sino que incluyen importantes antecedentes históricos en innumerables sitios, pintorescos paisajes y poblados junto a manifestaciones culturales que abarcan desde la producción artesanal hasta las festividades tradicionales de carácter religioso y civil. Porque dichos valores de tan diferente carácter y de una cualidad excepcional, constituyen su riqueza y su atractivo para públicos con intereses diversos dentro de abanico variado de un turismo cultural alternativo. 


\section{Apostillas anexas}

Al tratarse de un proyecto a mitad de elaboración es un tanto aventurado plantear conclusiones definitivas. A modo de cierre sin embargo y en la idea de que estas apostillas puedan ser de utilidad para quien quiera emprender la aventura de estudiar a los fines de la gestión, un paisaje cultural y con la salvedad de que las mismas son discutibles, ya que una golondrina no hace verano, se transmiten a continuación. Gustosamente se recibirán sugerencias o críticas que las corrijan o las enriquezcan.

\section{En relación a la Región:}

Para conocer la región se hace necesario estudiar sus componentes básicos: soporte físico (natural y construido), estructura vital (población, idiosincrasia y cultura, organización política, social y económica, en sus procesos históricos), estableciendo las interrelaciones de cada momento entre el hombre y su territorio. En consecuencia la identidad de una región es una imagen reconocible compartida por el inconsciente colectivo que relaciona lo físico geográfico del paisaje con lo histórico cultural de los habitantes.

El paisaje cultural se define por las interrelaciones entre un medio físico, un proceso histórico compartido, una sociedad que lo ocupa, una cultura común y una determinada lógica de generación de recursos.

La imagen cultural de la región conserva al mismo tiempo, invariantes de la historia y rasgos que van cambiando. Hay componentes más estables, como el medio físico y las esencias culturales, y otros más mutables como los componentes sociales, provocados por diferentes motivos como las comunicaciones 0 las migraciones de población. Sin embargo los más cambiantes son los procesos económicos. Todos influyen en su identidad ya que éste es un concepto con cierto grado de dinamismo.

Para descubrir las permanencias y los cambios de todos los componentes, es aconsejable adoptar el criterio de hacer cortes periódicos en los factores más dinámicos: la economía y lo social, estudiando la incidencia que ellos han tenido en la conservación de los invariantes y en los cambios que han introducido en la identidad regional.

El paisaje actual está configurado por todas las transformaciones originadas en cada etapa histórica, incluidos los aportes de los inmigrantes.

Una normativa en gran medida contribuye a crear una imagen determinada.

La relación del hombre con el paisaje es recíproca y se manifiesta reiterativamente en comportamientos, gustos y actitudes. 
Para un grupo social las configuraciones del espacio local regional constituyen la base de su memoria colectiva y el cimiento indispensable para su funcionamiento ( $\mathrm{H}$. Coing y Pierre Bourdieu).

La identidad es un concepto dinámico que va cambiando a lo largo de la historia dentro de períodos de "largas duraciones".

Lo igual y lo diferente caracterizan la identidad. El ser humano necesita para su realización personal tanto de la permanencia como del cambio.

Las corrientes migratorias en nuestro territorio fueron tejiendo sus costumbres, sus modos de vida en la realidad local y modelando tanto el medio físico natural como el construido, dejando una impronta que hacía referencia a su lugar de origen, pero que era a la vez "otra".

El lenguaje es solo un rasgo de la identidad, aunque no el único.

\section{En relación a los asentamientos:}

Naturaleza y ciudad se fecundan mutuamente según las tradiciones locales. La escala en general la impone el sitio, con sus bordes o límites, sus áreas homogéneas, sus hitos y nodos.

Para tener un conocimiento amplio de los lugares se hacen necesarias lecturas a escalas diferentes que corresponden a visiones diferentes: la macro del urbanista, técnica y racional, y la visión micro, del arquitecto, más sensible y con una aproximación tridimensional.

Las estructuras organizativas permanentes, tales como trazados urbanos, amplitud de calles, escalas de las manzanas, tipologías urbano-arquitectónicas y configuraciones espaciales son rasgos de identidad importantes.

Las costumbres, mitos y ritos, las artesanías y el arte son rasgos de identidad ineludibles y deben estudiarse tanto como los rasgos materiales.

Los mapas de percepción, compartidos por un grupo social, son rasgos de identidad.Ayudan a definir itinerarios de un paisaje cultural. 


\section{Bibliografía}

\section{BIBLIOGRAFÍA GENERAL INDICATIVA}

Benévolo, L. El diseño de la ciudad, Gustavo Gili. Barcelona, 1978.

Castex, J. et alt. Formas Urbanas de la manzana al bloque. Gustavo Gili. Barcelona, 1983.

Cerasi, M. La lectura ambiental. Edit. Infinito, Buenos Aires, 1975.

Forman Richard et alt: Landscape Ecology Principles in Landscape Architecture and Land Use Planning

Krier, L.. El espacio urbano -teoría y práctica-. Gustavo Gili. Barcelona, 1983.

Lefebvre. Le droit a la ville. Anthropos, 1966 y la Revolution Urbaine, París, 1977.

Lynch, K. La imagen de la ciudad. MIT, 1963.

Morris, A. E., Historia de la forma urbana. Gustavo Gili. Barcelona, $1979 .$.

Muratori, S. Studi per una operante storia urbana di Venezia. Roma, Instituto Paleográfico del Estado, 1989. Naselli, C. De ciudades, formas y paisajes. Arquina. Asunción del Paraguay, 1992.

Pannerai, Ph. et alt.. Elementos de Análisis Urbano. IEAL. Madrid, 1983.

\section{BIBLIOGRAFÍA ESPECÍFICA}

Foglia, M. E. y Goytía, N. Los poblados históricos del norte cordobés, Córdoba, 1993.

National Park Service. Definición de los paisajes culturales: Historic Site, Historic Vernacular Landscape, Ethnographic Landscape.

Unesco documentos para la definición de paisajes: Clearly Defined Landscape, Organically evolved landscape, Associative Cultural Landscape

Sabaté, Joaquín. L'eix patrimonial del Llobregat. Diputaciò de Barcelona.2000

Sabaté, Joaquín: Projectant l'eix del Llobregat. Paisatje cultural i desenvolupament regional. Universitat Politècnica de Catalunya y Massachusetts Institute of Technology. Barcelona 2001.

Sabaté Joaquín. Patrimonio y proyecto territorial. Espai Blau. Diputación de Barcelona. Barcelona 2003

Sabaté, Joaquín. Llocs amb esdiveniment. Event Places. Editores UPC y MIT. Barcelona, 2004.

\section{BIBLIOGRAFÍA ARGENTINA Y LATINOAMERICANA EN GENERAL}

Floriá y García Belsunce, Historia de los argentinos. Buenos Aires, 1985. 
Furlong, ,G. S.J. "Historia social y cultural del Río de la Plata 1536-1810". Tipográfica Editora Argentina, Buenos Aires 1969 Tomo "El trasplante cultural: Arte".

Serrano, A. "Los comechingones". Córdoba, Colección Peña UNC, 1945.

"El precerámico en la República Argentina y países vecinos". Dirección General de Publicaciones de la Universidad Nacional de Córdoba, Córdoba,1968.

"Los aborígenes argentinos. Síntesis etnográfica". Editorial Nova. Biblioteca americanista. Buenos Aires ,1947.

\section{BIBLIOGRAFÍA ARGENTINA Y LATINOAMERICANA EN ARQUITECTURA Y URBANISMO}

Hardoy, J. E. y Morse, R. Nuevas perspectivas en los estudios sobre historia urbana latinoamericana. GEL. Buenos Aires, 1989.

Hardoy. J. E. y Schaedel, R. Las ciudades de América Latina y sus áreas de influencia a través de la historia SIAP. Buenos Aires, 1976.

Morosi, J. y Vitaloni, C., Perduración de las normas indianas en el urbanismo argentino, y otros títulos; Anales LINTA, CIC, Buenos Aires, 1992 y 93.

Razzori, A., Historia de la ciudad argentina. Imprenta López. Buenos Aires, , 1945.

Summa-Historia: Arquitectura colonial argentina, 1987. Documentos para una historia de la arquitectura argentina. Buenos Aires, 1978.

\section{BIBLIOGRAFÍA DE HISTORIA Y GEOGRAFÍA DE CÓRDOBA}

Albarracín, Bosquejo histórico, político y económico de la provincia de Córdoba. Cordoba, 1905.

Instituto Geográfico Militar: Planchas geográficas y de lectura satelital.

Canals,S. Poblaciones indígenas de la Argentina. Editorial Sudamericana Buenos Aires 2a Edición 1973

Ibarra, D. E. Argentina indígena y prehistoria americana. Tipografía Editora Argentina, Buenos Aires, 1971.

Miatello, Geografía de Córdoba, Banco de la Provincia, 1991.

Publicaciones de municipios diversos: Córdoba, San Francisco, Marcos Juárez, Las Varillas, etc. Río y Achával, Geografía de la provincia de Córdoba. Banco de Córdoba. Cordoba, 1905.

Rojas de Villafañe, E. "La economía de Córdoba en el siglo XIX". Publicado por la Revista de Economía del Banco de la Provincia de Córdoba, Córdoba,1976

Terzaga. A. Geografía de Córdoba. Assandri, Córdoba, 1963. 


\section{BIBLIOGRAFÍA DE HISTORIA DE LAARQUITECTURA Y EL URBANISMO DE CÓRDOBA}

Gallardo, R. "Sus escritos sobre arquitectura de Córdoba" Editado por Facultad de Arquitectura, Urbanismo y Diseño, Universidad Nacional de Córdoba. Cordoba, 1995.

Fernández, J.A.: "Memorial de la patria chica. San Francisco del Chañar". Edición del autor sin data.

Foglia, M. E. y Goytía, N. et alt. El significado de la cuadrícula en la ciudad hispanoamericana: el caso Córdoba. Córdoba, 1987, 1993.

Goytía, N. y Foglia, M. E. Los procesos de modernización en Córdoba. Córdoba, 1989.

Provincia de Córdoba, Ministerio de la Función Pública y otros. Estudio sobre los centros rurales de la provincia. Sistema de centros y varios.

\section{BIBLIOGRAFÍA SOBRE PATRIMONIO Y TURISMO}

Ballart,J.. y Tresseras,J.J.Gestión del patrimonio cultural. Editorial Ariel. Barcelona, 1996.

Foglia, M. y Goytía N. "El patrimonio urbanístico ambiental de las regiones argentinas: Los poblados históricos del norte cordobés". Secretaría de Turismo de la Provincia de

Córdoba. Córdoba, 1993.

Foglia,M E. "Evolución de los criterios de intervención en el patrimonio", págs. 14 a 27 en Summarios Na 25; "Preservación más allá del discurso" Ediciones Summa Mayo-Junio 1988 Buenos Aires.

Klaus Koenig,G.: "Revitalizaciones perversas", págs. 3 a 13 en Summarios № 25 op. cit.

Mercado,R. y Moore, M. Atlas turístico de la provincia de Córdoba. Edición autores. Cordoba, 2003

Samar, L. y otros. Guía Turística YPF. 4:Centro y Noroeste. Editorial San Telmo. Buenos Aires, 1998.

Vinaccia, G. Conferencia: "Design \& identidades locales. La identidad cultural como factor de competitividad en los mercados mundiales". Facultad de Arquitectura Urbanismo y Diseño, Universidad Nacional de Córdoba. Setiembre, 1999.

\section{BIBLIOGRAFÍA SOBRE GESTIÓN:}

Aquino,J. Et alt. Recursos Humanos. Ediciones Macchi, $2^{\circ}$ edición, Buenos Aires, 1996.

Herminia,J., Serra, R. y Kastika, E. Administración y estrategia. $4^{0}$ edición. Ediciones Macchi, Buenos Aires.,1992. 